\title{
Detection of ALDH3B2 in Human Placenta
}

\author{
Sylwia Michorowska ${ }^{1, *(\mathbb{D})}$, Joanna Giebułtowicz ${ }^{1}$,, Renata Wolinowska ${ }^{2}$, Anna Konopka ${ }^{3}$, \\ Anna Wilkaniec ${ }^{4}$, Paweł Krajewski ${ }^{5}$, Ewa Bulska ${ }^{3}$ and Piotr Wroczyński ${ }^{1}$ \\ 1 Department of Bioanalysis and Drug Analysis, Faculty of Pharmacy, Medical University of Warsaw, \\ 02-097 Warsaw, Poland; joanna.giebultowicz@wum.edu.pl (J.G.); piotr.wroczynski@wum.edu.pl (P.W.) \\ 2 Department of Pharmaceutical Microbiology, Centre for Preclinical Research and Technology (CePT), \\ Faculty of Pharmacy, Medical University of Warsaw, 02-097 Warsaw, Poland; \\ renata.wolinowska@wum.edu.pl \\ 3 Biological and Chemical Research Centre, Faculty of Chemistry, University of Warsaw, 02-097 Warsaw, \\ Poland; a.konopka@cnbc.uw.edu.pl (A.K.); ebulska@chem.uw.edu.pl (E.B.) \\ 4 Department of Cellular Signaling, Mossakowski Research Centre, Polish Academy of Sciences, \\ Pawińskiego 5, 02-106 Warsaw, Poland; awilkaniec@imdik.pan.pl \\ 5 Forensic Medicine Department, First Faculty of Medicine, Medical University of Warsaw, 02-097 Warsaw, \\ Poland; pawel.krajewski@wum.edu.pl \\ * Correspondence: ssolobodowska@wum.edu.pl
}

Received: 7 November 2019; Accepted: 11 December 2019; Published: 13 December 2019

\begin{abstract}
Aldehyde dehydrogenase 3B2 (ALDH3B2) gene contains a premature termination codon, which can be skipped or suppressed resulting in full-length protein expression. Alternatively, the longest putative open reading frame starting with the second in-frame start codon would encode short isoform. No unequivocal evidence of ALDH3B2 expression in healthy human tissues is available. The aim of this study was to confirm its expression in human placenta characterized by the highest $A L D H 3 B 2$ mRNA abundance. ALDH3B2 DNA and mRNA were sequenced. The expression was investigated using western blot. The identity of the protein was confirmed using mass spectrometry (MS). The predicted tertiary and quaternary structures, subcellular localization, and phosphorylation sites were assessed using bioinformatic analyses. All DNA and mRNA isolates contained the premature stop codon. In western blot analyses, bands corresponding to the mass of full-length protein were detected. MS analysis led to the identification of two unique peptides, one of which is encoded by the nucleotide sequence located upstream the second start codon. Bioinformatic analyses suggest cytoplasmic localization and several phosphorylation sites. Despite premature stop codon in DNA and mRNA sequences, full-length ALDH3B2 was found. It can be formed as a result of premature stop codon readthrough, complex phenomenon enabling stop codon circumvention.
\end{abstract}

Keywords: $A L D H 3 B 2$; premature stop codon; placenta; readthrough

\section{Introduction}

$A L D H 3 B 2$ gene, also known as $A L D H 8$, belongs to the aldehyde dehydrogenase (ALDH) gene superfamily [1]. This superfamily consists of 19 putatively functional genes [2] that encode enzymes catalyzing the $\mathrm{NAD}(\mathrm{P})+$-dependent irreversible oxidation of aldehydes to the corresponding carboxylic acids. The importance of their physiological, detoxification, and protective functions is evidenced by the fact that mutations and polymorphism of $A L D H$ genes, resulting in a decreased or lost enzymatic activity, lead to severe diseases such as Sjögren-Larsson syndrome, cancer, and Alzheimer's disease to name a few [2,3]. The majority of ALDH proteins have been well characterized by now. So far, there is 
no information available about function of ALDH3B2 isozyme and data related to its expression in healthy human individuals are ambiguous.

The ALDH3B2 gene located on human chromosome 11q13.2 consists of at least 10 exons [4]. It exhibits high structural similarity to the $A L D H 3 B 1$ gene. The numbers and positions of the introns, as well as the boundaries of the individual exons of the two genes, are precisely conserved [4]. The two genes have relatively high nucleotide positional identities in the corresponding coding regions (86\%) [5]. However, at the 17th codon (starting from the first start codon) premature in-frame stop codon was identified in the cDNA sequence of $A L D H 3 B 2$. The possibility of it being the product of a variant $A L D H 3 B 2$ gene allele was verified by sequencing genomic DNA fragments containing the variant codon isolated from 10 unrelated people of the Asian population by Hsu and Chang [5]. The analysis revealed that all PCR products contained the termination codon, suggesting that $A L D H 3 B 2$ gene could be a non-processed pseudogene [5]. However, it was found that seven CpG dinucleotides in ALDH3B2 gene-related amplicon had decreased mean methylation levels in sperm DNA obtained from males with reduced fecundity in comparison to control (the proven fertile males) [6]. The observed CpG methylation pattern indicates that $A L D H 3 B 2$ gene is active and its expression is controlled by an epigenetic mechanism. Depending on the location of $\mathrm{CpG}$ sites their hypermethylation can result in either increased (when located in a gene body) or decreased (when located in promoters or enhancers) gene expression [7].

ALDH3B2 mRNA was found in human salivary glands by Hsu and Chang [5] and in small intestine, colon, kidney, lung, stomach, testis, thymus, thyroid gland, trachea, pancreas, uterus, prostate, salivary gland, and placenta by Nishimura and Naito [8] by reverse transcriptase PCR (RT-PCR) analysis, which indicates that this gene is transcribed. The premature stop codon found in ALDH3B2 mRNA can be eliminated by alternative splicing, RNA editing [4], or translational recoding.

Regulation of gene expression at the translational level can be achieved via the following three recoding events: stop-codon readthrough, ribosome frameshifting, and translational bypassing. The first phenomenon does not alter the translational reading frame and extends the polypeptide C-terminally [9]. Stop codon can be decoded as a sense codon by either a near-cognate tRNA (tRNA with anticodons that have a single mismatch upon pairing to a stop codon) or the specialized cognate tRNAs (tRNAs with an anticodon that is complementary to the stop codon), such as tRNA ${ }^{\text {Sec }}$ [9]. Both of these recoding events would result in the full-length ALDH3B2 expression (466 amino acids (aa), molecular weight around $53 \mathrm{kDa}$; longer variant shown in Figure 1). Failing to maintain the correct reading frame in the production of protein results in ribosome frameshifting in - or + direction. Spontaneous frameshifting produces non-functional peptides while programmed ribosome frameshifting (which is the frameshifting enhanced by the signals in the mRNA) typically leads to the synthesis of a functional polypeptide from an altered frame. The third mentioned recoding event, translational bypassing, produces a single protein from a discontinuous reading frame. A portion of the mRNA is skipped by the translating ribosome leading to the production of only one polypeptide from a discontinued frame. In case of the $A L D H 3 B 2$ gene, the ribosome could translate the first 16 mRNA codons up to the UGA stop codon. Then instead of terminating protein synthesis, the ribosome could slide over a non-coding gap and continue the synthesis after reaching the matching landing codon, which in case of $A L D H 3 B 2$ would be first downstream AAG triplet, as the matching take-off and landing codon is the key bypassing signal [9]. Translational bypassing would result in the production of a protein a little bit shorter than the full-length isoform (466 aa), but longer than the short one (385 aa). Alternatively, the translation of $A L D H 3 B 2$ transcript containing premature stop codon can be started from the second start codon (that is the first downstream in-frame ATG codon). In case of such a scenario, the protein produced would be 385 aa long (molecular weight around $43 \mathrm{kDa}$; shorter isoform shown in Figure 1), thus shorter than typical ALDH proteins, but still containing regions important for catalytic functions characteristic of this group of enzymes [5]. 


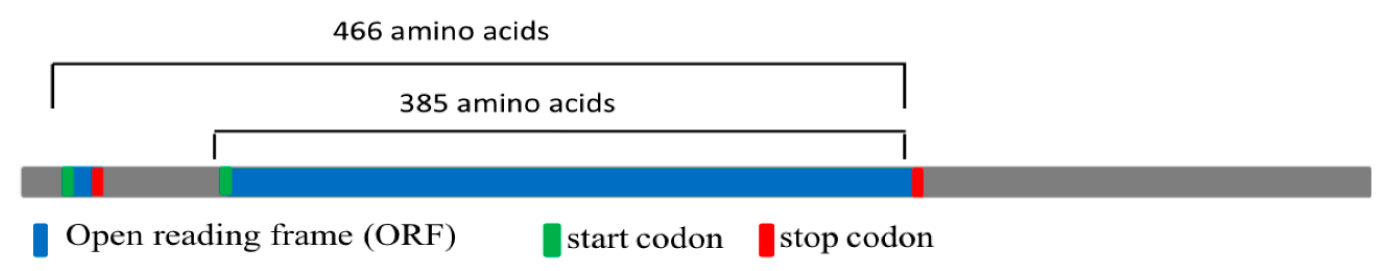

Figure 1. Structure of $A L D H 3 B 2$ gene. Blue represents open reading frames (ORF), green represents the start codon, and red represents the stop codon. Black lines show lengths of two ALDH3B2 isoforms: the short one with 385 amino acids and the long one with 466 amino acids.

Two unique ALDH3B2 peptides were detected in proteomic analysis of forty human lung adenocarcinoma cell lines [10]. These peptides were assigned to short ALDH3B2 isoform, which may indicate that only peptides mapping to protein region encoded by nucleotide sequence located downstream of the second start codon were identified. However, identification of peptides mapping to the sequence of short ALDH3B2 isoform does not provide conclusive evidence of the presence of short ALDH3B2 variant in cell lines subjected to the analysis, as such peptides could originate from either short or long ALDH3B2 isoform. Unfortunately, neither their sequences, nor their mass spectra, are available for evaluation. Moreover, some ALDH isozymes are known to be differently expressed in healthy and cancerous tissues (e.g., ALDH1A3 [11]) and literature data indicate elevated ALDH3B2 mRNA levels in lung squamous cell carcinoma and lung adenocarcinoma compared to healthy tissues [12]. The only available data about ALDH3B2 protein expression in healthy human tissues can be found in the Human Proteome Map database [13]. Sequences and mass spectra of the following peptides were identified: HLTPVTLELGGK, VTLELGGK, NPCYVDDNCDPQTVANR, FYGDDPQSSPNLGR, YFNAGQTCVAPDYVLCSPEMQER, and LLPALQSTITR [13]. However, careful evaluation revealed that none of them is unique to ALDH3B2. The high sequence homology of ALDH3B1 and ALDH3B2 makes the differentiation between those two isoenzymes extremely challenging.

The $A L D H 3 B 2$ DNA sequence analysis results that are available only for Asian population and ambiguous data concerning the detection of ALDH3B2 protein in cell lines and human tissues do not provide conclusive evidence for ALDH3B2 expression in humans. Thus, the aim of this study was to confirm the expression of ALDH3B2 protein in healthy human tissues by western blot and mass spectrometry analyses. Additionally, to shed some light on ALDH3B2 expression mechanism, sequencing analyses of genomic DNA, and mRNA isolated from Caucasian race individuals were performed. All tests were conducted on placenta samples as this tissue was found to express the highest levels of $A L D H 3 B 2$ mRNA as found by Nishimura and Naito [8].

\section{Results}

\subsection{Recombinant Protein Expression in Escherichia coli and Western Blot Analysis}

Both short and long isoforms of ALDH3B2 protein were obtained using pET28a(+)-E. coli expression system (Figure 2). These recombinant proteins were used as positive controls in western blot analyses and enabled the selection of the appropriate gel bands for cutting out in the in-gel digestion protocol used in mass spectrometry analyses.

Western blot analysis of placenta homogenates revealed no bands corresponding to the mass 43 $\mathrm{kDa}$. Surprisingly, bands corresponding to a greater mass, around $53 \mathrm{kDa}$, were obtained (Figure 3). 


\section{Recombinant}

ALDH

3B2

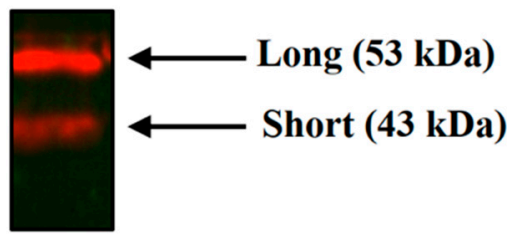

Figure 2. Western blot analysis using anti-ALDH3B2 antibody confirmed the expression of both short and long isoforms of recombinant ALDH3B2 protein in E. coli. Purified recombinant proteins were applied onto the polyacrylamide gel. After separation, they were transferred onto the PVDF membrane. Their immunodetection was performed using anti-ALDH3B2 antibody. The image was taken using ChemiDoc XRS+ (Bio-Rad).

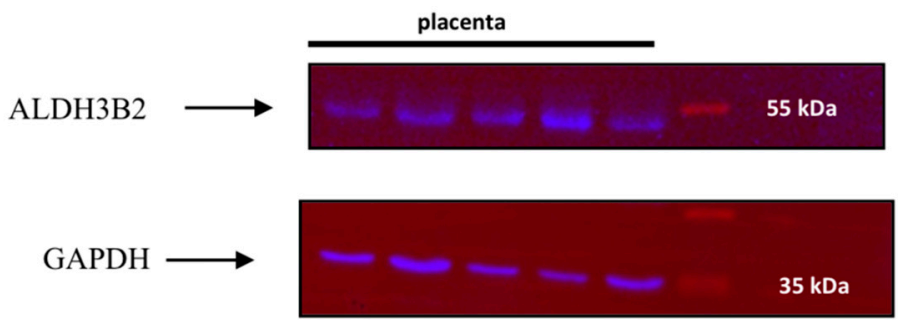

Figure 3. Western blot analysis of placenta homogenates using anti-ALDH3B2 and anti-GAPDH antibodies revealed bands corresponding to the molecular weight of $53 \mathrm{kDa}$ (long isoform of ALDH3B2) and bands corresponding to molecular weight of $37 \mathrm{kDa}(\mathrm{GAPDH})$. Proteins in homogenates were applied onto the polyacrylamide gel. After separation, they were transferred onto the PVDF membrane. Immunodetection of ALDH3B2 protein was performed using anti-ALDH3B2 antibody. After membrane stripping, the immunodetection was repeated with anti-GAPDH antibody. GAPDH detection was used as a loading control, as GAPDH gene is constitutively expressed at high levels in many tissues. The image was taken using ChemiDoc XRS+ (Bio-Rad). Additionally, the image of the whole membrane was added into the Supplementary Materials (Supplementary Figure S1).

\subsection{DNA and RNA Analyses}

Genomic DNA isolated from placenta samples as well as ALDH3B2 mRNA RT-PCR products contained premature stop codon at the 17th codon position downstream the 1st start codon (Figures 4 and 5). No allelic variants were detected.

\begin{tabular}{|c|c|}
\hline NG_012255 & 3574 GCCACCCCATCCGGCAGC ATGGACCCCTTCGAGGACACGCTGCGGCGGCTGCGTGAGGCCTTCA A TGAGGGCGCACGO \\
\hline$\ll C-P L R$ & 48 GCCACCCCATCCGGCAGCATGGACCCCTTCGAGGACACGCTGCGGCGGCTGCGTGAGGCCTTCAMdTGAGGGCGC \\
\hline «B-PLR & 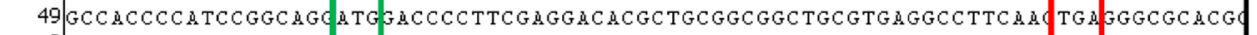 \\
\hline »S-PLF & 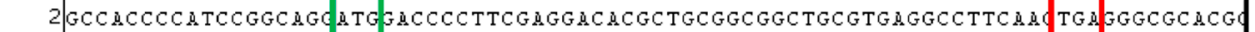 \\
\hline \& A-PFR & 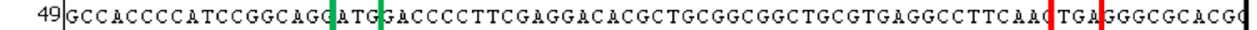 \\
\hline$\ll S-P L R$ & 49 GCCACCCCATCCGGCAGCATGGACCCCTTCGAGGACACGCTGCGGCGGCTGCGTGAGGCCTTCÄATGAGGGC \\
\hline «M-PLR & 49 GCCACCCCATCCGGCAGCATGGACCCCTTCGAGGACACGCTGCGGCGGCTGCGTGA \\
\hline »M-PLF & 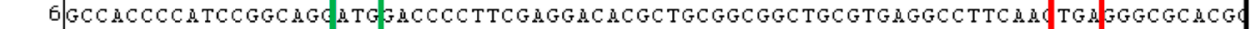 \\
\hline 》C-PLF & ATGGACCCCTTCGAGGACACGCTGCGGCGGCTGCGTGA \\
\hline \#-PLF & ATGGACCCCTTCGAGGACACGCTGCGGCGGCTGCGTGAC \\
\hline »A.PLF & TGGACCCCTTCGAGGACACGCTGCGGCGGCTGCGTGAGGCCTTCA A TG. \\
\hline
\end{tabular}

Figure 4. All sequences of $A L D H 3 B 2$ DNA isolated from placenta samples contained premature stop codon. Sequence alignment was performed using Vector NTI Advance ${ }^{\mathrm{TM}} 11.0$ software. As a reference ALDH3B2 sequence from NCBI (NG_012255.1) was used. Green frame shows first start codon and red one premature stop codon. 


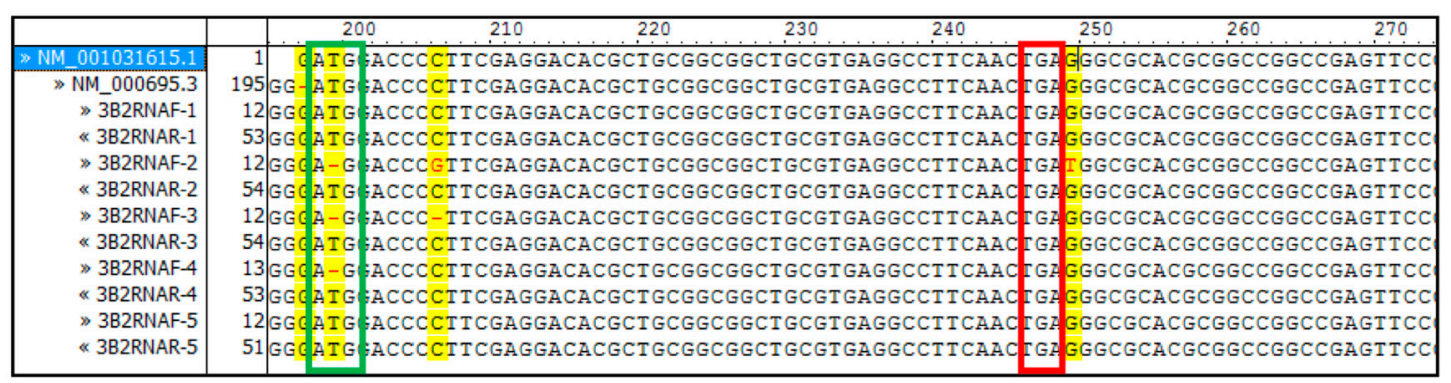

Figure 5. All sequences of $A L D H 3 B 2$ cDNA synthesized in RT-PCR reaction using mRNA isolated from placenta samples contained premature stop codon. Sequence alignment was performed using Vector NTI Advance $^{\mathrm{TM}} 11.0$ software. Isolated RNA was treated with DNase to remove contaminating DNA and then subjected to RT-PCR. The obtained cDNA was sequenced. As a reference, ALDH3B2 cDNA sequences from NCBI (NM_001031615.1 and NM_000695.3) were used. The green frame shows first start codon and red frame shows the premature stop codon. Yellow indicates differences in the aligned sequences.

\subsection{MS/MS Analysis}

Long ALDH3B2 and ALDH3B1 isoforms' peptides were found among the tryptic fragments of proteins present in placenta homogenates. The identified amino acid sequences were as follows: LLPALQSTITR and FYGDDPQSSPNLGR - peptides common to ALDH3B1 as well as both, short and long ALDH3B2; AAQLQGLGHFLQENK—peptide unique to long ALDH3B2; and LDYIFFTGSPR-a peptide common to long and short ALDH3B2, but not present in the sequence of ALDH3B1.

The MS/MS spectra for the sequencing of two of them, AAQLQGLGHFLQENK and LDYIFFTGSPR, are shown in Figures 6 and 7, respectively.

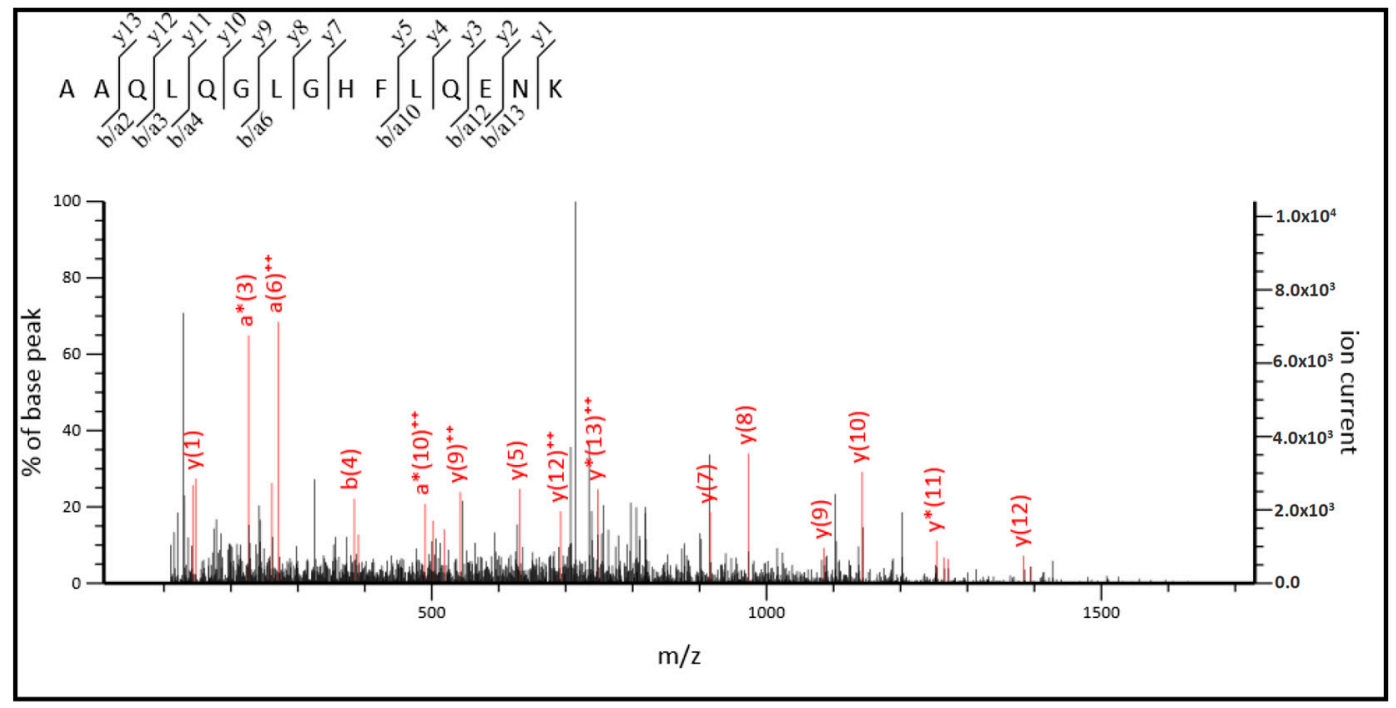

Figure 6. MS/MS spectrum for the tryptic peptide, AAQLQGLGHFLQENK, found in the sequence of long ALDH3B2 isoform. The upper left corner indicates the source of the fragment ions identified as either $b$, a, or y ions. ${ }^{++}$designates doubly charged fragment ions, ${ }^{*}$ designates fragment ions with neutral loss. 
As it can be observed in Figure 8, three out of four identified peptides correspond to the part of the sequences common to both, short, and long ALDH3B2 isoforms. Among the observed peptides only one is unique to this isoenzyme (LDYIFFTGSPR) and differs by only one amino acid when compared to the corresponding sequence of ALDH3B1 (FDYIFFTGSPR). The fourth identified peptide (AAQLQGLGHFLQENK) is encoded by the nucleotide sequence located upstream the second start codon, indicating the presence of long ALDH3B2 isoform. Its sequence differs by only one amino acid (histidine) from the corresponding sequence of ALDH3B1, AAQLQGLGRFLQENK (arginine). Detailed analysis of MS/MS spectrum registered for AAQLQGLGHFLQENK peptide (Figure 6) indicates the presence of $y 7$ fragment ion with the amino acid sequence HFLQENK proving the presence of histidine residue in the peptide structure, thus confirming the identification of long ALDH3B2 in the placenta homogenate. The corresponding AAQLQGLGRFLQENK sequence characteristic of ALDH3B1 after trypsin digestion would give two short peptides since $\mathrm{R}$ is a cleavage site for trypsin. Even if this cleavage site is missed by enzyme, what sometimes happens, $\mathrm{m} / \mathrm{z}$ registered for this amino acid sequence would be different (the mass difference between $H$ and $R$ residues is 19.0422). In the similar way, peptide sequence LDYIFFTGSPR, which is common to the long and short ALDH3B2 differs by one amino acid residue (leucine) from the corresponding ALDH3B1 peptide sequence FDYIFFTGSPR (phenylalanine). In MS/MS spectra recorded for LDYIFFTGSPR (Figure 7), b3 (LDY), b7 (LDYIFFT), and b9 (LDYIFFTGS) fragment ions were identified, all containing leucine in their structures. This proves the presence of long (and/or short) ALDH3B2 isoform.

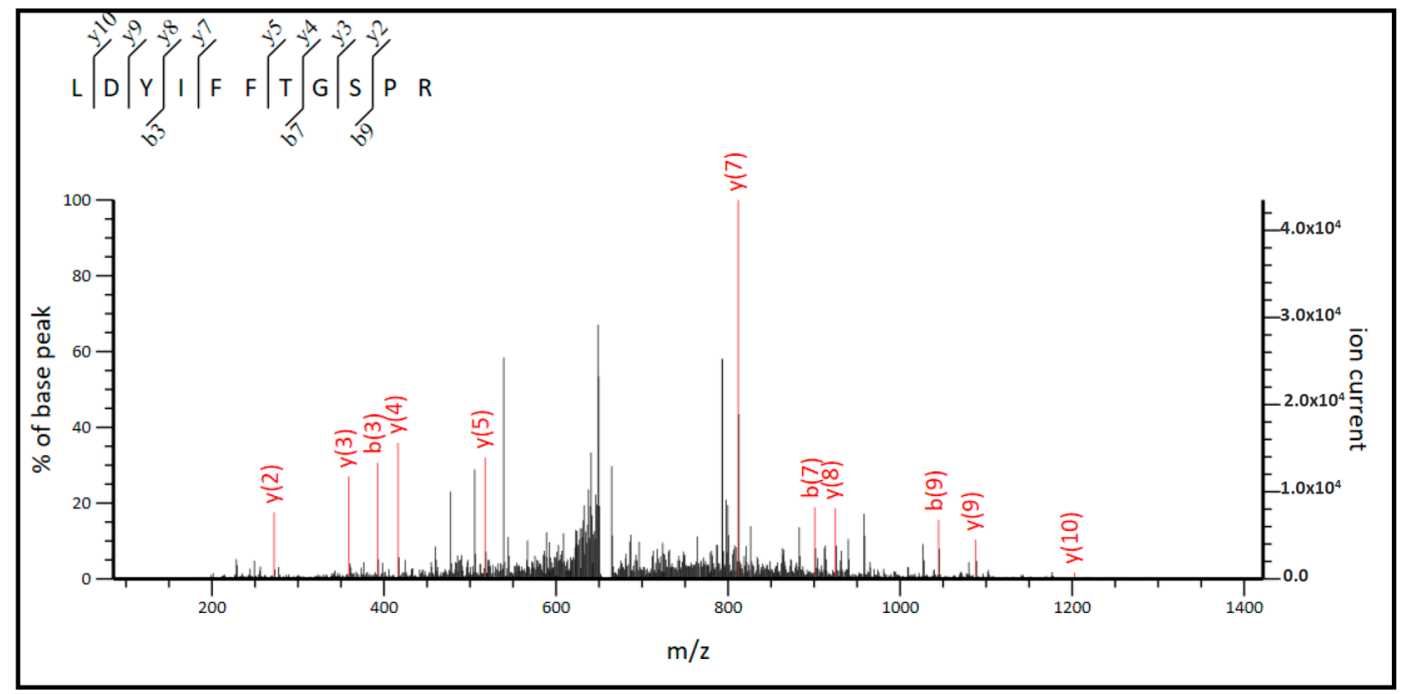

Figure 7. MS/MS spectrum for the tryptic peptide, LDYIFFTGSPR, found in the sequence of long and short ALDH3B2 isoform. The upper left corner indicates the source of the fragment ions identified as either $\mathrm{b}$ or $\mathrm{y}$ ions.

As a control experiment, proving the successful use of MS/MS analysis to verify the presence of long ALDH3B2 isoform in placenta homogenate, a recombinant long ALDH3B2 protein was analyzed. Amino acids sequences identified as well as MS/MS spectrum registered for AAQLQGLGHFLQENK unique to long ALDH3B2 are presented in Supplementary Materials (Supplementary Figure S3). For the recombinant protein six unique peptides, present in the part of the protein encoded by nucleotides located upstream the second start codon, were identified. 


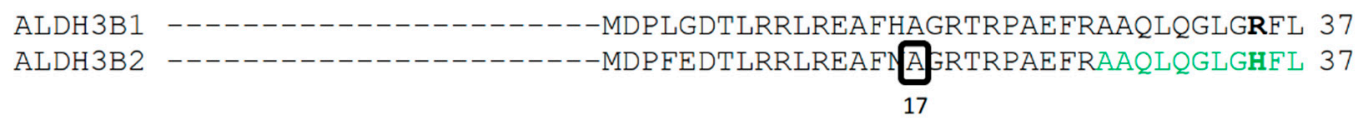

ALDH3B1 QENKQLLHDALAQDLHKSAFESEVSEVAISQGEVTLALRNLRAWMKDERVPKNLATQLDS 97 ALDH3B2 QENKQLLRDVLAQDLHKPAFEADISELILCQNEVDYALKNLQAVMRDEPRSTNLFMKLDS 97

ALDH3B1 AFIRKEPFGLVLIIAPWNYPLNLTLVPLVGALAAGNCVVLKPSEISKNVEKILAEVLPQY 157 ALDH3B2 VFIWKEPFGLVLI IAPWNYPLNLTLVLLVGALAAGSCVVLKPSEISQGTEKVLAEVLPQY 157

ALDH3B1 VDQSCFAVVLGGPQETGQLLEHRFDYIFFTGSPRVGKIVMTAAAKHLTPVTLELGGKNPC 217 ALDH3B2 LDQSCFAVVLGGPQETGQLLEHKLDYIFFTGSPRVGKIVMTAATKHLTPVTLELGGKNPC 217

ALDH3B1 YVDDNCDPQTVANRVAWFRYFNAGQTCVAPDYVLCSPEMQERLLPALOSTITRFYGDDPQ 277 ALDH3B2 YVDDNCDPQTVANRVAWFCYFNAGQTCVAPDYVLCSPEMQERLIPALQSTITRFYGDDPQ 277

ALDH3B1 SSPNLGRIINQKQFQRLRALLGCGRVAIGGQSDESDRYIAPTVLVDVQEMEPVMQEEIFG 337 ALDH3B2 SSPNLGHIINQKQFQRLRALLGCGRVAIGGQSNESDRYIGPTVLVDVQETEPVMQEEIFG 337

ALDH3B1 PILPIVNVQSLDEAIEFINRREKPLALYAFSNSSQVVKRVLTQTSSGGFCGNDGFMHMTL 397 ALDH3B2 PILPIVNVQSVDEAIKFINRQEKPLALYAFSNSRQVVNQMLERTSSGSFGGNEGFTYISL 397

ALDH3B1 ASLPFGGVGASGMGRYHGKFSEDTFSHHRACLLRSPGMEKLNALRYPPQSPRRLRMLLVA 457 ALDH3B2 LSVPFGGVGHSGMGRYHGKFTFDTFSHHRTCLLAPSGLEKLKEIHYPPYTDWNQQLLRWG 457

$\begin{array}{lll}\text { ALDH3B1 } & \text { MEAQGCSCTLL } & 468 \\ \text { ALDH3B2 } & \text { MGSQSCTLL-- } & 466\end{array}$

Figure 8. Peptides identified in MS/MS analysis of placenta homogenates. Peptide sequences identified in the MS/MS analysis were mapped to the long ALDH3B2 isoform sequence (translation product of mRNA transcript number U37519.1 from NCBI obtained using ExPASy server [14] with alanine in the position encoded by premature stop codon) and compared with the sequences of the corresponding peptides of ALDH3B1 (NCBI: NP_001154945.1). Colors indicate sequences of identified peptides: yellow and violet-sequences common to ALDH3B1 as well as short and long ALDH3B2; blue-sequence common to both, short and long ALDH3B2 isoforms; and green-sequence unique to long ALDH3B2 isoform. Residues in bold represent amino acids different for ALDH3B1 and ALDH3B2 within sequences of identified peptides. Grey shading indicates positions of different amino acids present in different ALDH3B2 natural variants that can be found in UniProt database [15]: residue 50: A/T, residue 52: S/N, residue 203:H/R, residue 220: G/S, residues 276: $R / W$, residue 302: $S / R$, residue 361: H/R. Two black frames in the sequence of ALDH3B2 indicate: the alanine in the position encoded by the premature stop codon (17th aa) and methionine encoded by the first in-frame start codon (82nd aa), respectively.

\subsection{Bioinformatic Analysis}

The alignment of all ALDH3 isoenzymes' sequences, including the sequence of long ALDH3B2 isoform with alanine in the position encoded by the premature stop codon, is shown in Figure 9. 


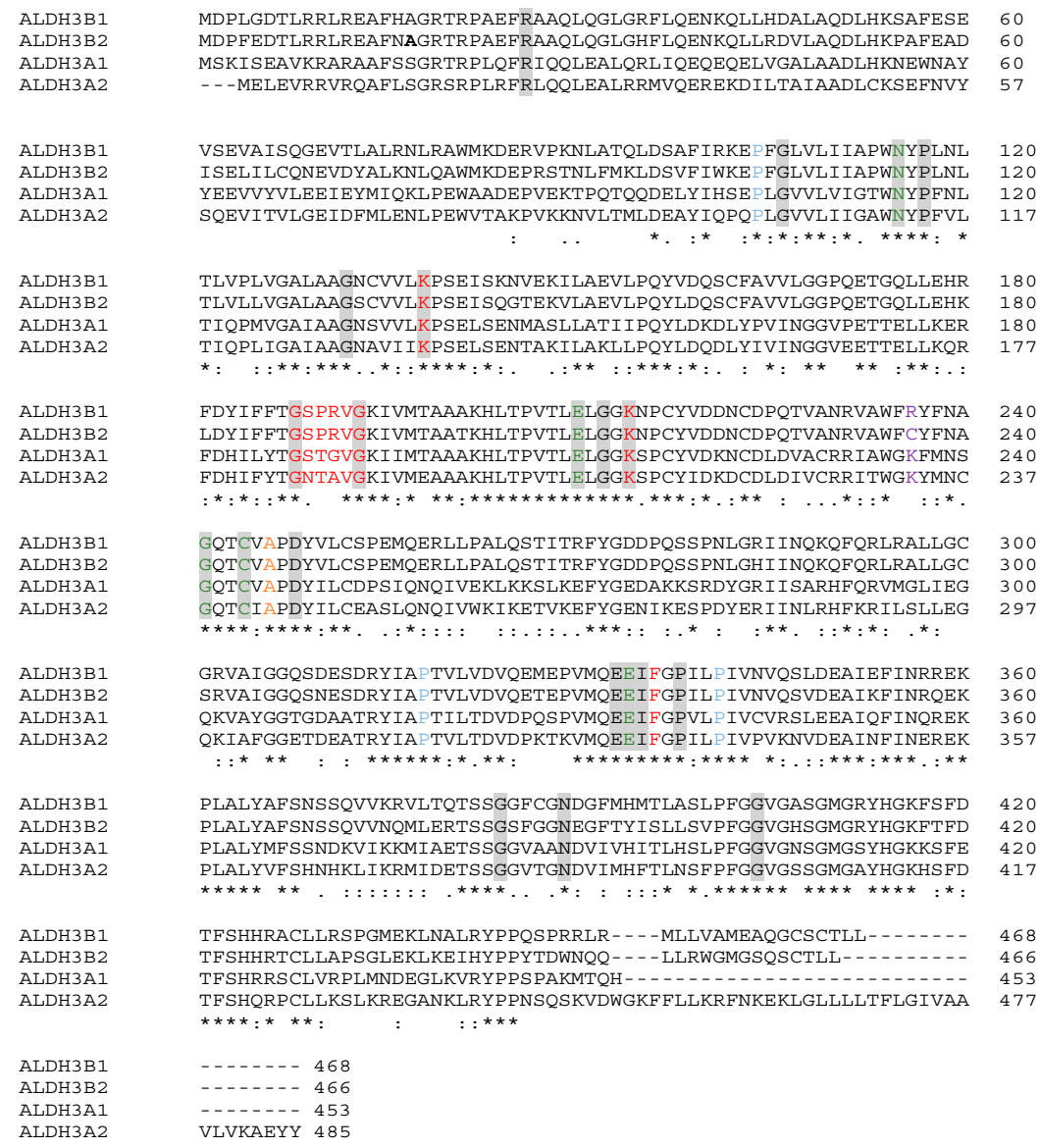

Figure 9. Comparison of ALDH3 isoenzymes' primary structures. The alignment of ALDH3 sequences was performed using Clustal Omega server [16] and the following sequences: NCBI sequence NP_001128640.1 of ALDH3A1, NCBI sequence NP_000373.1 of ALDH3A2, NCBI sequence NP_001154945.1 of ALDH3B1 and long ALDH3B2 isoform sequence, the product of translation of mRNA transcript number U37519.1 from NCBI obtained using ExPASy server [14], with alanine in the position encoded by premature stop codon. Orange indicates residues involved in substrate binding, red residues involved in cofactor binding, blue three proline residues contributing to the tertiary structure, violet residue 236, gray shading residues highly conserved: Cys-244 acting as a nucleophile; Glu-334 activating thiol group of Cys-244; Gly-241 positioning Cys-244; Glu-210 activating water molecule that hydrolyzes ester group, residues responsible for cofactor binding: Gly-188 and Gly-193 forming Rossmann fold; Lys-138, Glu-334, and Phe-336 responsible for nicotinamide ring positioning and hydrogen bond formation to the $\mathrm{NAD}(\mathrm{P})^{+}$adenine ribose; Ile-335 and Lys-214 ensuring appropriate geometry of cofactor binding domain; Asn-115 crucial for catalytic activity, transiently stabilizing oxygen of carboxyl group of tetrahedral intermediate; Asp-248 conserved in ALDHs belonging to the third subfamily, responsible for appropriate geometry of active site; Arg-26, Gly-106, Pro-117, Gly-132, Pro-338, Gly-384, Asn-389, and Gly-404 [1,17].

Twenty-two residues were found to be highly conserved in ALDH3 subfamily. These include active site residues (Asn-115, Glu-210, Cys-244, Glu-334), 15 glycine residues (e.g., Gly-188 and Gly-212 located within the stem of the active funnel, Gly-188 and Gly-193 forming the Rossmann fold), and three proline residues (Pro-103, Pro-318 and Pro-341 contributing to the tertiary structure) [17]. As it can be observed in Figure 9, all highly conserved residues are present in the sequence of long ALDH3B2 isoform, including Asp-248 being the residue the most indicative of class 3 ALDH. However, attention should be paid to the residue 236, whose function was elucidated in the context of Sjögren-Larsson syndrome. In the case of ALDH3A2, Lys-236 is known to protonate the transient oxyanion formed 
during the catalysis [1]. Replacing it with cysteine present in this position in ALDH3B2 may affect enzyme activity.

The predicted tertiary and quaternary structures of long ALDH3B2 isoform are depicted in Figure 10.
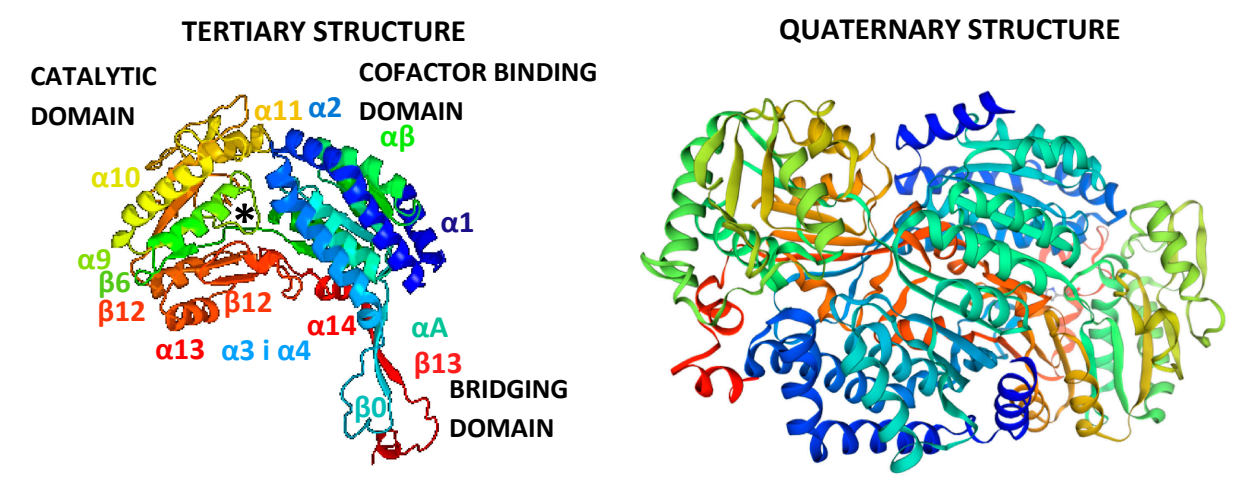

Figure 10. Predicted tertiary and quaternary structure of human long ALDH3B2 isoform, with alanine in the position encoded by the premature stop codon. The tertiary structure model was prepared using Phyre2 server [18] and the quaternary structure model was prepared using Swiss Model server [19]. ALDH3B2 sequence used was the product of translation of mRNA transcript number U37519.1 from NCBI obtained using ExPASy server [14], with alanine in the position encoded by premature stop codon. In both cases, the rat class 3 aldehyde dehydrogenase template at $2.6 \AA$ resolution was used (PDB ID: 1AD3). The confidence was 100\%, coverage 95\% (444 residues: 4-447) with 50\% sequence identity. The rainbow color code describes the predicted 3D structures from $\mathrm{N}$ - (blue) to C-termini (red). The designation of the three domains as well as that of alpha helices and beta strands was based on the rat ALDH3A1 structure (PDB ID: 1AD3) [20]. The asterisk indicates the catalytic Cys-244.

The first tertiary structures of class 2 and 3 ALDH were published in 1996-1997 [20,21] and as of today crystal structures of several human ALDH are described in literature, e.g., ALDH1A1 [22], ALDH1A3 [23], ALDH2 [24], ALDH3A1 [24], 3A2 [25], ALDH4A1 [26]. Among ALDHs both, dimers and tetramers can be found. The predicted tertiary structure for human long ALDH3B2 isoform was compared with rat ALDH3A1. Similar structures were observed including the three major domains: the catalytic domain, the NAD binding domain and an oligomerization domain, involved in the dimer formation (Figure 10). The two first mentioned domains are separated by the active site cleft [1]. The quaternary structure shows the homo-dimer. The Global Model Quality Estimation (GMQE) is 0.77 indicating high reliability. The value of QMEAN Z-score $(-0.01)$ indicates good agreement between the model structure and experimental structures of similar size.

Low probability of transmembrane helices formation by long ALDH3B2 isoform was obtained using TMHMM Server v. $2.0[27,28]$ (Supplementary Figure S4). However, another analysis using SOSUI server [29] showed the possibility of two transmembrane helices formation: one between 118 and 140 amino acid residues and second one between 151 and 173 amino acid residues.

The subcellular localization predicted using WoLF PSORT server [30] suggests, that long ALDH3B2 isoform is a cytoplasmic protein, while the sequence analysis performed using NetPhos 3.1 [31] suggested several possible phosphorylation sites.

\section{Discussion}

All genomic DNA samples analyzed in this study confirmed the presence of the premature stop codon in ALDH3B2 gene in Caucasian population as detected by Hsu and Chang in Asian population [5]. This excludes the possibility of it being the variant gene allele. The presence of the premature stop codon in DNA does not necessarily indicate its presence in mRNA transcripts due to the changes in their sequences introduced by alternative splicing or RNA editing. However, in case of ALDH3B2 
mRNA premature stop codon was identified suggesting at first, that short isoform of protein, if any, is expressed in human tissues. It is interesting though, that in analyzed placenta homogenates band corresponding to the protein with greater mass (around $53 \mathrm{kDa}$ ) was detected by western blot analysis.

Taking into account questionable reliability of western blot analysis, the identity of the protein detected was confirmed by MS/MS analysis. Two peptides unique to ALDH3B2 were identified in placenta homogenates, among them one mapping to the region upstream the premature stop codon, indicating the expression of the longer variant. It must be emphasized though, that the sequences of each of the observed peptides have only one amino acid that is different for ALDH3B2 and ALDH3B1. According to the UniProt database [15] ALDH3B1 has no natural variants identified so far, which enables assigning those two peptides, AAQLQGLGHFLQENK and LDYIFFTGSPR, to the long isoform of ALDH3B2 isozyme.

Sequence analysis of long ALDH3B2 isoform confirmed the presence of all highly conserved residues in this family of enzymes. However, the presence of cysteine at 236 position (in place of lysine in case of ALDH3A1 and ALDH3A2, and arginine in case of ALDH3B1) suggests the possibility of altered enzymatic activity, which should be assessed experimentally. Mouse ALDH3B2 located in lipid droplets is characterized by broad substrate specificity including medium- and long-chain aldehydes [32]. However, the primary structure of human and mouse ALDH3B2 are not identical. What is more, the amino acid residue in mouse ALDH3B2 that corresponds to the 236 amino acid position of human ALDH3B2 is arginine. Because of the differences in the primary structure the predictions about substrate specificity using mouse enzyme would be rather far-fetched. Additionally, because of the possibility of phosphorylation of some of ALDH3B2 residues, the activity should be determined experimentally, best using purified human enzyme.

The mass of the detected ALDH3B2 protein corresponds to the mass of the protein encoded by the nucleotide sequence starting with the first ATG codon. Observation of the full-length protein would mean that somehow the premature termination codon identified in mRNA sequence is skipped or suppressed. The process of protein synthesis termination is not $100 \%$ efficient [33]. There are several ways in which reading frames can be extended by circumventing stop codons including translational bypassing, in-frame suppression of termination codons and ribosomal frame shifting [34]. The peptides identified by mass spectrometry analyses can exclude the possibility of ribosomal frame shifting to be the only process enabling the premature stop codon elimination in case of ALDH3B3 mRNA, as this process would produce a protein with different primary structure. During the translational bypassing of $A L D H 3 B 2$ mRNA the ribosome would take-off after reaching AAG codon, which precedes the premature UGA codon. The first matching landing codon is located 23 triplets downstream the premature stop codon. The peptide AAQLQGLGHFLQENK identified in MS/MS analysis is encoded by the nucleotide sequence starting with 10th codon downstream the premature stop codon (Supplementary Figure S5), which excludes the possibility of translation bypassing as the mechanism of the recoding event occurring during the expression of $A L D H 3 B 2$ gene. It is possible that long ALDH3B2 isoform is produced as a result of spontaneous stop codon readthrough. This phenomenon has been well documented in viruses [35], bacteria, yeast [36], and Drosophila [37]. The frequency of the occasional readthrough is low $<10^{-4}$ per stop codon $[33,38]$ but it can be increased up to $0.1-0.3$ due to the stimulating effects of sequence and structural elements in the mRNA as well as trans factors [39,40]. Moreover, in-frame premature stop codons represent a genotypic subset of mutations that make up $\sim 11 \%$ of all known mutations that cause genetic diseases, and millions of patients have diseases attributable to premature termination codons [41].

First example of eukaryotic mammalian readthrough protein was rabbit $\beta$-globin, whose mRNA contains premature UGA stop codon [34,42]. Mass spectrometry analysis of isolated rabbit $\beta$-globin led to the identification of sequences of seven different proteolytic peptide fragments that were encoded by the same mRNA sequence containing premature stop codon. Four of them were formed as a result of readthrough (with serine, tryptophan, cysteine, and arginine being inserted during the stop codon decoding). The other three lacked an amino acid or amino acids corresponding to the stop codon 
and/or one or two of the neighboring nucleotides, which indicates that they were produced as a result of translational reading gap [34]. There are two other experimentally confirmed readthrough proteins: longer isoform of myelin protein zero ( $\mathrm{p} 0$ or MPZ), so called large myelin protein zero (L-MPZ) [43], and vascular endothelial growth factor-A isoform (VEGF-Ax) with unique 22-amino acid C-terminal extension and anti-angiogenic activity expressed in mammalian endothelial cells [40]. In the case of the latter example, the stop codon is decoded as serine [40]. AGO1 and MTCH2 genes are authentic readthrough targets identified by bioinformatics analysis and transfection experiments using HEK293 cells [40].

Human selenoproteins are formed by the incorporation of selenocysteine (Sec) dictated by in-frame UGA codon. This complex mechanism requires special trans-acting protein factors (Sec insertion sequence binding protein 2 and Sec-specific translation elongation factor) and a cis-acting Sec insertion sequence (SECIS) element (a stem-loop structure located immediately downstream of the in-frame UGA codon at which Sec is incorporated) [9,44]. For the decoding of a stop codon by near cognate tRNA, genomic analyses, and profiling studies of human genes have found several potential readthrough candidates [9] some of which were confirmed experimentally. About $4 \%$ of malate dehydrogenase is physiologically extended by translational readthrough, with arginine and tryptophan being co-encoded by the UGA stop codon [45]. C-extended isoform of human lactate dehydrogenase is produced as a result of readthrough of UGA-CUA motif [46]. Readthrough of the vitamin D receptor mRNA sequence UGACUAG results in an expression of a protein with 67 amino acid-long C-terminal extension (vitamin $\mathrm{D}$ receptor $\mathrm{X}$ ). This longer proteoform is characterized by a reduced transcriptional response to calcitriol [47]. An interesting example of premature stop codon readthrough is the $L A M A 3$ gene (R943X/R1159X). In one patient carrying heterozygous nonsense mutation of LAMA3 gene, it was observed that $L A M A 3$ mRNA escaped nonsense-mediated decay, which resulted in the expression of full length laminin $\alpha 3$ [48].

The MS/MS data collected in this study do not allow for unequivocal elucidation of the mechanism of premature stop codon elimination in case of $A L D H 3 B 2$. Unfortunately, peptide corresponding to the nucleotide sequence encompassing premature TGA codon was not detected. However, one possibility consistent with the data collected is that ALDH3B2 protein can be produced in the process of the stop codon readthrough resulting from the decoding by near-cognate tRNA.

Figure 11 shows the fragment of the $A L D H 3 B 2$ mRNA sequence, including premature stop codon.

\section{$-6-5-4-3-2-1+1+2+3+4+5+6+7+8+9$}

\section{UUCAACUGAGGGCGC}

Figure 11. Nucleotide sequence surrounding the premature stop codon in ALDH3B2 mRNA.

There are several factors known to affect the efficiency of stop codon readthrough. These include the stop codon itself [49], nucleotide sequence surrounding the stop codon [50], transacting factors [36,51], abundance of near-cognate tRNAs [52], abundance and/or modifications of release factors [53], and the presence of mRNA secondary structures $[39,54,55]$. Research on mammalian cell lines showed that opal stop codon is characterized by the highest potential of undergoing the process of readthrough [56-60]. Moreover, nucleotides surrounding premature termination codon may interact with nucleotides of the near-cognate acyl-tRNA anticodon loop and consequently stabilize codon-anticodon binding, facilitating the incorporation of an amino acid (Arg, Cys, Trp, Ser, for TGA or Gln for TAG) [34,48,61]. In yeasts, six nucleotides preceding and following the TAG are most influential [62,63]. It was found that readthrough is favored by the presence of two adenines at position -1 and -2 [63]. Other research indicates the substantial role of the nucleotide immediately downstream the stop codon as evidenced by its interaction with the release factors [59], which are involved in the mechanism of translation termination [33]. The nucleotide following the premature termination codon in ALDH3B2 contains guanine. High readthrough level in experiments using mammalian cell lines was found 
for cytidine in this position [60]. However, adenine present at -2 position of ALDH3B2 gene can induce the readthrough by structural modification of mRNA at P-site of ribosome [63]. What is more, in certain cases the deviation from one of the 'canonical' readthrough motif may be tolerated [39]. In the case of the $L A M A 3$ gene mutation R943X, the first and third nucleotides upstream of the premature termination codon or one of the two nucleotides following the premature termination codon had the following consensus sequence (A/T) (A/G) (T/C) TGA CTA. There are also other factors affecting the readthrough. In case of VEGF-Ax, this phenomenon is promoted by the binding of heterogeneous nuclear ribonucleoprotein (hnRNP) A2/B1 (trans-factor) to the cis-acting element located in the $3^{\prime}$ UTR region of the sequence [40]. Cis-acting RNA structures can also modulate the readthrough by interfering with release factor recruitment to the ribosome, by modulating ribosome function through the interaction with ribosomal proteins or rRNAs and also by inducing ribosome stalling [9]. In the case of some viruses and Drosophila genes, the stimulatory element for efficient readthrough includes a stem-loop structure that spans $\sim 140 \mathrm{nt} 3^{\prime}$ of the stop codon. It is possible that this secondary mRNA structure interacts with ribosome directly (pausing it and/or promoting its conformational changes) or provides a physical block that preferentially occludes release factor from the A-site in favor of tRNAs [39]. The complex phenomenon of stop codon decoding by near-cognate tRNA awaits further elucidation.

Sequencing the readthrough protein at the site encoded by the stop codon is crucial to determine whether ALDH3B2 is formed by readthrough or by another mechanism. Helpful would be the overexpression of $A L D H 3 B 2$ gene fragment starting with the first start codon and containing the premature stop codon in HEK293 cells, the subsequent purification of the product and its sequence analyses. An alternative way of confirming the readthrough of $A L D H 3 B 2$ mRNA could involve the use of aminoglycosides, which are known to induce premature termination codon readthrough in E. coli, yeast, and human cultured cells [64].

\section{Materials and Methods}

\subsection{Preparation of Placenta Homogenates}

All procedures were carried out on ice. Dissected and frozen human placenta obtained after Caesarean section of women at the Infant Jesus Teaching Hospital, Warsaw Medical University $(n=12)$ were rinsed with ice cold PBS three times and homogenized manually using $5 \mathrm{mmol} \mathrm{dm}^{-3}$ phosphate buffer $\mathrm{pH}=7.2$ containing $0.25 \mathrm{~mol} \mathrm{dm}{ }^{-3}$ sucrose and protease inhibitor cocktail (cOmplete ${ }^{\mathrm{TM}}$ Mini EDTA-free Protease Inhibitor Cocktail; Roche). To remove chromosomal DNA, cell debris, and fibers, the homogenates were centrifuged at $10,000 \times \mathrm{g}$ for $10 \mathrm{~min}$ and the supernatants were collected and stored at $-80^{\circ} \mathrm{C}$. The protein concentration was determined using Bradford assay kit (Thermo Scientific ${ }^{\mathrm{TM}}$, Waltham, MA, USA) to standardize the amount of protein subjected to gel electrophoresis and subsequent western blot.

\subsection{Expression of ALDH3B2 in E. coli}

In the first step short isoform of recombinant ALDH3B2 (385 aa) was produced using the human $A L D H 3 B 2$ gene fragment starting with the second start codon amplified from "TrueClone" cDNA clone in pCMV6-XL5 vector purchased from OriGene. The sequences of the $5^{\prime}$ and $3^{\prime}$ PCR primers were:

5'GGGCTAGCATGAAGGATGAACCACGGTC3' and

5'GGGAATTCTCACAGGAGGGTGCAGCTC3' respectively

A NheI site was introduced by the PCR primer on the $5^{\prime}$ end, whereas a EcoRI site on the $3^{\prime}$ end. The resulting 1.5-kb PCR-amplified fragment was digested with NheI and EcoRI, gel-purified using the QIAquick Gel Extraction Kit (Qiagen), and ligated with pET-28a(+) vector (Novagene) that has been digested with the same restriction enzymes and gel-purified. The product of the ligation reaction was used to transform E.coli BL-21 (DE3) competent cells (Invitrogen). The sequence of the entire insert of the plasmid was verified by sequencing. 
The cultures of the overproducing strain were grown at $37^{\circ} \mathrm{C}$ in LB broth $(35 \mathrm{~g} / \mathrm{L}$ tryptone, $20 \mathrm{~g} / \mathrm{L}$ yeast extract, $5 \mathrm{~g} / \mathrm{L} \mathrm{NaCl}$, Sigma-Aldrich) supplemented with $50 \mu \mathrm{g} / \mathrm{mL}$ kanamycin to an $\mathrm{OD}_{600}$ of 0.6. The expression was induced by adding IPTG (isopropyl $\beta$-D-1-thiogalactopyranoside, Sigma-Aldrich) to a final concentration of $1 \mathrm{mmol} \mathrm{dm}^{-3}$. Recombinant ALDH3B2 was isolated with Ni-NTA Fast Start Kit (Qiagen) and dialyzed overnight to $50 \mathrm{mM}$ pyrophosphate buffer containing $1 \mathrm{mM}$ EDTA and $1 \mathrm{mM}$ DDT (Sigma-Aldrich).

To obtain long ALDH3B2 isoform, the human ALDH3B2 gene was subjected to mutagenesis to transform the premature stop codon TGA into GCA, codon encoding alanine. The choice of amino acid was dictated by the presence of alanine in the same position in ALDH3B1 protein having the highest sequence homology. The plasmid containing $A L D H 3 B 2$ gene fragment starting with the first start codon and containing the premature stop codon was amplified in PCR reaction using two primers phosphorylated at $5^{\prime}$ end with the following sequences:

5'GGCCTTCAACGCAGGGCGCA3' (bearing point mutation) and

5'TCACGCAGCCGCCGC3'.

There, PCR was performed the following way: 1 cycle of initial denaturation at $98^{\circ} \mathrm{C}$ for $30 \mathrm{~s}$, 25 cycles of subsequent denaturation at $98^{\circ} \mathrm{C}$ for $10 \mathrm{~s}$, annealing at $72{ }^{\circ} \mathrm{C}$ for $15 \mathrm{~s}$, and extension at 72 ${ }^{\circ} \mathrm{C}$ for $30 \mathrm{~s}$, followed by 1 cycle of final extension at $72{ }^{\circ} \mathrm{C}$ for $10 \mathrm{~min}$.

The parental methylated and hemimethylated DNA was digested with FastDigest Dpnl (Phusion ${ }^{\mathrm{TM}}$ Site-Directed Mutagenesis Kit, Thermo Scientific, Waltham, MA, USA) according to the manufacturer's instructions. The mutated PCR product was circularized by ligation with T4 DNA Ligase (Phusion ${ }^{\mathrm{TM}}$ Site-Directed Mutagenesis Kit, Thermo Scientific, Waltham, MA, USA). After confirming its sequence, it was used to transform E. coli.

\subsection{Western Blot Analyses}

The supernatants obtained after placenta homogenates centrifugation and recombinant proteins samples were denatured and fractionated by sodium dodecyl sulfate-polyacrylamide gel electrophoresis (SDS-PAGE). Separated proteins were transferred onto polyvinylidene difluoride (PVDF) membrane using a transfer apparatus (mini-PROTEAN Tetra Cell, Bio-Rad) according to the manufacturer's protocol. After incubation with $5 \%$ non-fat milk in TBST $\left(10 \mathrm{mmol} \mathrm{dm}{ }^{-3}\right.$ Tris, $\mathrm{pH} 8.0,150 \mathrm{mmol} \mathrm{dm}^{-3}$ $\mathrm{NaCl}, 0.5 \%$ Tween 20) for $60 \mathrm{~min}$, membranes were washed three times with TBST. Human ALDH3B2 protein was detected using goat anti-human ALDH3B2 antibody (1:200, v/v) (Santa Cruz Biotechnology, Inc., Dallas, TX, USA) by incubation at $4{ }^{\circ} \mathrm{C}$ for $12 \mathrm{~h}$. After being washed three times, membranes were incubated with horseradish peroxidase-conjugated (HRP) anti-goat antibody $(1: 40,000)$ (Sigma-Aldrich) for $1 \mathrm{~h}$. Finally, proteins bound with antibody were visualized using chemiluminescence (Pierce ECL Western Blotting Substrate, Thermo Scientific, Waltham, MA, USA) and ChemiDoc XRS+ imaging system (Bio-Rad). Loading of protein samples was confirmed by reprobing membranes with rabbit anti-human glyceraldehyde 3-phosphate dehydrogenase (GAPDH) antibody (1:40,000 (v/v)) followed by peroxidase-conjugated anti-rabbit IgG (1:8000, Sigma-Aldrich). The detection of GAPDH also enabled the assessment of the quality of the experiment, e.g., proper transfer of the proteins from the gel onto the membrane. In the preliminary experiments, two different primary anti-ALDH3B2 antibodies were used: an affinity purified goat polyclonal antibody raised against a peptide mapping within an internal region (15-20 amino acid residues between 310 and 360 (numbering based on short ALDH3B2 isoform) of ALDH3B2 of human origin (T-13 Santa Cruz Biotechnology, sc-109919, Dallas, TX, USA) and an affinity purified rabbit polyclonal antibody raised against peptide mapping to 135-341 amino acid residues region of human ALDH3B2 (Novus Biologicals, NBP1-31716, Centennial, CO, USA). Their specificity was assessed by performing western blot analyses with recombinant ALDH1A1 and ALDH3A1 proteins that were available in our laboratory. None of these two ALDH recombinant proteins mentioned above produced bands in western blot analyses with primary antibody obtained from Santa Cruz Biotechnology (Supplementary Figure S2). Furthermore, to assess the possibility of this antibody to cross-react with ALDH3B1 protein, which could not be evaluated 
experimentally, the primary structures of the two ALDH3B proteins were compared revealing that within the epitope recognized by anti-ALDH3B2 antibody obtained from Santa Cruz Biotechnology sixteen amino acid residues are different for those two isozymes. That is why this antibody was used in further experiments.

Western blot analyses were also performed using other tissues homogenates such as ovaries and colons. The results of these analyses are shown in Supplementary Figure S2.

\subsection{DNA Analysis}

Genomic DNA was isolated from placenta fragments using Genomic Mini (A\&A Biotechnology) and subjected to sequence analysis with the following primers:

$5^{\prime}$ TGGAGGGTGCCCGTGAAG3' and

5' CCCTCCTGAAAGAGGACAGG3'

Primers were designed to amplify the sequence containing the premature stop codon. The obtained sequences were analyzed using Vector NTI Advance ${ }^{\mathrm{TM}} 11.0$ software. As a reference $A L D H 3 B 2$ sequence from NCBI (NG_012255.1) was used.

\subsection{RNA Analysis}

Placenta fragments were stored in RNAlater solution (Life Technologies) and then homogenized using PRO 200 homogenizer (PRO Scientific). RNA was isolated using EXTRACTME TOTAL RNA kit (DNA Gdańsk) according to the manufacturer's instructions. Contaminating DNA was removed using DNA-free kit (Life Technologies). Pure RNA was subjected to reverse transcription and subsequent polymerase chain reactions using MyTaq ${ }^{\mathrm{TM}}$ One-Step RT-PCR kit (Bioline). Primers were designed to amplify the sequences containing the premature stop codon and their sequences were the following:

5'CAAGAAAGGGAGTGGAGGTG3' and

5'TCCAGATGAAGACCGAGTCC $3^{\prime}$.

RT-PCR was performed on a T100 Thermal Cycler (Bio-Rad) the following way: 1 cycle of reverse transcription at $45^{\circ} \mathrm{C}$ for $20 \mathrm{~min}, 1$ cycle of polymerase activation at $95^{\circ} \mathrm{C}$ for $1 \mathrm{~min}, 40$ cycles of subsequent denaturation at $95^{\circ} \mathrm{C}$ for $10 \mathrm{~s}$, annealing at $60^{\circ} \mathrm{C}$ for $10 \mathrm{~s}$, and extension at $72{ }^{\circ} \mathrm{C}$ for $30 \mathrm{~s}$.

Sequence alignment was performed using Vector NTI Advance ${ }^{\mathrm{TM}} 11.0$ software. As a reference ALDH3B2 cDNA sequences from NCBI (NM_001031615.1 and NM_000695.3) were used.

\subsection{Protein Identification by UHPLC-ESI-MS/MS Analysis}

In order to further verify the presence of ALDH3B2 in placenta homogenates an ultra-high performance liquid chromatography electrospray mass spectrometry (UHPLC-ESI-MS/MS) was applied. The proteins were resolved by SDS-PAGE. Gel bands, selected according to the molecular weight of ALDH3B2, were cut out and digested by trypsin (Trypsin Gold, Mass Spectrometry Grade purchased from Promega, Madison, WI, USA) according to the in-gel digestion standard protocol involving reduction and alkylation steps. Protein digestion was stopped by formic acid addition and obtained peptides were extracted from the polyacrylamide gel. Peptide mixtures were concentrated in a vacuum centrifuge and resuspended in $0.1 \%$ formic acid in water $(v / v)$. UPLC-ESI-MS/MS analyses were performed using Dionex UltiMate 3000 RSLCnano system (Thermo Fisher Scientific, Waltham, MA, USA) coupled to Orbitrap Fusion Tribrid mass spectrometer (Thermo Fisher Scientific). Peptides' samples were loaded first onto the trap column Acclaim PepMap100 C18, particle size $5 \mu \mathrm{m}$, pore size $100 \AA, 300 \mu \mathrm{m}$ i.d. $\times 5 \mathrm{~mm}$ (Thermo Fisher Scientific, Waltham, MA, USA) at the flow rate of $10 \mu \mathrm{l} / \mathrm{min}$ of water with $0.1 \%$ formic acid and desalted for $7 \mathrm{~min}$. The injection volume was $20 \mu \mathrm{L}$. Acclaim PepMap100 C18, particle size $3 \mu \mathrm{m}$, pore size $100 \AA$, $75 \mu \mathrm{m}$ i.d. $\times 50 \mathrm{~cm}$ (Thermo Fisher Scientific, Waltham, MA, USA) was used as an analytical column. Peptides were eluted from both columns at the flow rate of $300 \mathrm{~nL} \mathrm{~min}^{-1}$ with the following linear gradient: $0 \mathrm{~min}-3 \% \mathrm{~B}, 8 \mathrm{~min}-3 \%$ B, $120 \mathrm{~min}-70 \% \mathrm{~B}, 130 \mathrm{~min}-70 \% \mathrm{~B}, 130.5 \mathrm{~min}-3 \% \mathrm{~B}$, and $150 \mathrm{~min}-3 \% \mathrm{~B}$ (solvent A-water $/ 0.1 \%$ formic acid, solvent $\mathrm{B}-80 \%$ acetonitrile $/ 20 \%$ water $/ 0.1 \%$ formic acid). Eluting peptides were ionized in 
the positive ion mode with a capillary voltage of $1.6 \mathrm{kV}$ and analyzed using an Orbitrap Fusion Tribrid mass spectrometer. Survey scans were recorded with the Orbitrap mass analyzer at a resolving power of 60,000 in the $\mathrm{m} / \mathrm{z}$ range of 350-1600 and from each survey scan the most abundant multiply charged ions were fragmented by higher energy collisional dissociation and collisional-induced dissociation. The product ions were analyzed in the Orbitrap mass analyzer at a resolving power of 15,000. Cycle time was $3 \mathrm{~s}$. After fragmentation the masses were excluded for $30 \mathrm{~s}$ from further fragmentation.

UPLC-ESI-MS/MS data was analyzed using Xcalibur 2.0.7 (Thermo Scientific, Waltham, MA, USA) and MASCOT 2.2.0.4. (Matrix Science, London, UK) [65]. The acquired MS/MS spectra were evaluated using UniProt database [15] to which the sequence of long ALDH3B2 isoform modified with alanine in the position encoded by premature stop codon (translation product of mRNA transcript number U37519.1 from NCBI obtained using ExPASy server [14] (https://web.expasy.org/translate/)) was added.

The MS/MS analysis was also performed for recombinant long ALDH3B2, as a control experiment, providing the successful use of MS/MS analysis to verify the presence of long ALDH3B2 isoform in placenta homogenate.

\subsection{Bioinformatic Analyses}

Translation of ALDH3B2 mRNA transcript (number U37519.1 from NCBI, Bethesda, MD, USA) was achieved using ExPASy server [14]. The product of this translation process with alanine in the position encoded by premature stop codon was used as 'long ALDH3B2' in other bioinformatic analyses described below. Peptide sequences identified in the MS/MS analysis were mapped to the long ALDH3B2 isoform sequence and compared with the sequences of the corresponding peptides of ALDH3B1 (NCBI: NP_001154945.1, Bethesda, MD, USA) using Clustal Omega server [16]. Sequence alignment of all four aldehyde dehydrogenase isoenzymes belonging to the third subfamily (NCBI sequence NP_001128640.1 of ALDH3A1, NCBI sequence NP_000373.1 of ALDH3A2, NCBI sequence NP_001154945.1 of ALDH3B1 and long ALDH3B2 isoform sequence, Bethesda, MD, USA) was performed using Clustal Omega server [16]. The tertiary and quaternary structure models of long ALDH3B2 isoform were obtained using Phyre2 server [18] and Swiss Model server [19], respectively. In both cases rat class 3 aldehyde dehydrogenase template at $2.6 \AA$ resolution was used (PDB ID: 1AD3). The confidence was $100 \%$, coverage $95 \%$ (444 residues: $4-447$ ) with $50 \%$ sequence identity. For the model obtained using Phyre2 software no backbone or sidechain relaxations were performed. The scientific group of Dr. Lawrence Kelley have found that using molecular dynamics to relax homology models typically worsens their accuracy in terms of superposability on the native structure. The backbone is inherited from the template based on the alignment and the sidechains are placed using the SCWRL algorithm based on a backbone-dependent rotamer library. Swiss Model uses the ProMod3 modelling engine where model relaxation is the last step. ProMod3 delegates the molecular mechanics energy calculations used for relaxation to the OpenMM library. The CHARMM27 forcefield in vacuum are evaluated and relaxed iteratively. Each iteration consists of 20 steps SD (steepest descent) and 10 steps LBFGS (Broyden-Fletcher-Goldfarb-Shanno). Iteration stops as soon as all stereo-chemical problems are resolved.

The probability of transmembrane helices was assessed for long ALDH3B2 using TMHMM Server v. $2.0[27,28]$ and SOSUI server [29], the prediction of subcellular localization using WoLF PSORT server [30] and that of phosphorylation sites using NetPhos 3.1 [31].

\section{Conclusions}

To the best of our knowledge, despite the presence of premature stop codon in mRNA sequence, longer ALDH3B2 isoform is expressed in human placenta representing full-length protein. It can be formed by premature stop codon readthrough, a complex phenomenon enabling stop codon circumvention. Long ALDH3B2 isoform may be a functional enzyme, as all, highly conserved in ALDH enzyme family amino acids residues involved in substrate and cofactor binding, as well as oligomerization are present in its sequence. However, its activity should be confirmed experimentally. 
Supplementary Materials: Supplementary materials can be found at http://www.mdpi.com/1422-0067/20/24/6292/s1.

Author Contributions: Conceptualization, S.M. and J.G.; Data analysis, S.M., J.G., R.W. and A.K.; Funding acquisition, S.M. and P.W.; Investigation, S.M. and J.G.; Methodology, S.M., R.W., A.K., and A.W.; Project administration, S.M. and J.G.; Resources, P.K. and P.W.; Supervision, E.B., P.W., and J.G.; Visualization, S.M.; Writing-Original draft, S.M.; Writing—Review \& editing, J.G., R.W., A.K., and A.W.

Funding: This research received no external funding.

Acknowledgments: The UHPLC-MS/MS experiments were carried out at the Biological and Chemical Research Centre, University of Warsaw, established within the project co-financed by European Union from the European Regional Development Fund under the Operational Programme Innovative Economy 2007-2013.The cloning and DNA analysis were performed using Centre for Preclinical Research and Technology infrastructure financed by the European Union-European Regional Development Fund within the "Innovative Economy" Operational Programme for 2007-2013. We would like to thank Lawrence Kelly and Gabriel Studer for their invaluable assistance in assessing the sidechain and backbone relaxations in the predicted tertiary and quaternary models of long ALDH3B2, when using Phyre2 and Swiss Model servers, respectively.

Conflicts of Interest: The authors declare no conflict of interest.

\section{Abbreviations}

$\begin{array}{ll}\text { RT-PCR } & \text { Reverse transcriptase PCR } \\ \text { ORF } & \text { Open reading frame } \\ \text { IPTG } & \text { Isopropyl } \beta \text {-D-1-thiogalactopyranoside } \\ \text { SDS-PAGE } & \text { Sodium dodecyl sulfate-polyacrylamide gel electrophoresis } \\ \text { PVDF } & \text { Polyvinylidene difluoride } \\ \text { HRP } & \text { Horseradish peroxidase-conjugated } \\ \text { GAPDH } & \text { Glyceraldehyde 3-phosphate dehydrogenase } \\ \text { p0/MPZ } & \text { Myelin protein zero } \\ \text { L-MPZ } & \text { Large myelin protein zero } \\ \text { hnRNP } & \text { Heterogeneous nuclear ribonucleoprotein } \\ \text { Sec } & \text { Selenocysteine }\end{array}$

\section{References}

1. Holmes, R.S.; Hempel, J. Comparative studies of vertebrate aldehyde dehydrogenase 3: Sequences, structures, phylogeny and evolution. Evidence for a mammalian origin for the ALDH3A1 gene. Chem. Biol. Interact. 2011, 191, 113-121. [CrossRef] [PubMed]

2. Marchitti, S.A.; Brocker, C.; Stagos, D.; Vasiliou, V. Non-P450 aldehyde oxidizing enzymes: The aldehyde dehydrogenase superfamily. Expert Opin. Drug Metab. Toxicol. 2008, 4, 697-720. [CrossRef] [PubMed]

3. Giebułtowicz, J.; Wroczyński, P.; Samolczyk-Wanyura, D. Can lower aldehyde dehydrogenase activity in saliva be a risk factor for oral cavity cancer? Oral Dis. 2013, 19, 763-766. [CrossRef] [PubMed]

4. Hsu, L.C.; Chang, W.C.; Yoshida, A. Human aldehyde dehydrogenase genes, ALDH7 and ALDH8: Genomic organization and gene structure comparison. Gene 1997, 189, 89-94. [CrossRef]

5. Hsu, L.C.; Chang, W.-C. Sequencing and expression of the human ALDH8 encoding a new member of the aldehyde dehydrogenase family. Gene 1996, 174, 319-322. [CrossRef]

6. Laqqan, M.; Tierling, S.; Alkhaled, Y.; Lo Porto, C.; Solomayer, E.F.; Hammadeh, M. Spermatozoa from males with reduced fecundity exhibit differential DNA methylation patterns. Andrology 2017, 5, 971-978. [CrossRef]

7. Jang, H.S.; Shin, W.J.; Lee, J.E.; Do, J.T. CpG and non-CpG methylation in epigenetic gene regulation and brain function. Genes 2017, 8, 148. [CrossRef]

8. Nishimura, M.; Naito, S. Tissue-specific mRNA expression profiles of human phase I metabolizing enzymes except for cytochrome P450 and phase II metabolizing enzymes. Drug Metab. Pharmacokinet. 2006, 21, 357-374. [CrossRef]

9. Rodnina, M.V.; Korniy, N.; Klimova, M.; Karki, P.; Peng, B.-Z.; Senyushkina, T.; Belardinelli, R.; Maracci, C.; Wohlgemuth, I.; Samatova, E.; et al. Translational recoding: Canonical translation mechanisms reinterpreted. Nucleic Acids Res. 2019. [CrossRef] 
10. Zhang, Q.; Taguchi, A.; Schliekelman, M.; Wong, C.-H.; Chin, A.; Kuick, R.; Misek, D.E.; Hanash, S. Comprehensive Proteomic Profiling of Aldehyde Dehydrogenases in Lung Adenocarcinoma Cell Lines. Int. J. Proteom. 2011, 2011, 1-8. [CrossRef]

11. Chen, M.-H.; Weng, J.-J.; Cheng, C.-T.; Wu, R.-C.; Huang, S.-C.; Wu, C.-E.; Chung, Y.-H.; Liu, C.-Y.; Chang, M.-H.; Chen, M.-H.; et al. ALDH1A3, the Major Aldehyde Dehydrogenase Isoform in Human Cholangiocarcinoma Cells, Affects Prognosis and Gemcitabine Resistance in Cholangiocarcinoma Patients. Clin. Cancer Res. 2016, 22, 4225-4235. [CrossRef] [PubMed]

12. Chang, P.M.-H.; Chen, C.-H.; Yeh, C.-C.; Lu, H.-J.; Liu, T.-T.; Chen, M.-H.; Liu, C.-Y.; Wu, A.T.H.; Yang, M.-H.; Tai, S.-K.; et al. Transcriptome analysis and prognosis of ALDH isoforms in human cancer. Sci. Rep. 2018, 8, 2713. [CrossRef] [PubMed]

13. Kim, M.-S.; Pinto, S.M.; Getnet, D.; Nirujogi, R.S.; Manda, S.S.; Chaerkady, R.; Madugundu, A.K.; Kelkar, D.S.; Isserlin, R.; Jain, S.; et al. A draft map of the human proteome. Nature 2014, 509, 575-581. [CrossRef] [PubMed]

14. Gasteiger, E.; Gattiker, A.; Hoogland, C.; Ivanyi, I.; Appel, R.D.; Bairoch, A. ExPASy: The proteomics server for in-depth protein knowledge and analysis. Nucleic Acids Res. 2003, 31, 3784-3788. [CrossRef]

15. Bateman, A.; Martin, M.J.; O’Donovan, C.; Magrane, M.; Alpi, E.; Antunes, R.; Bely, B.; Bingley, M.; Bonilla, C.; Britto, R.; et al. UniProt: The universal protein knowledgebase. Nucleic Acids Res. 2017, 45, D158-D169.

16. Sievers, F.; Wilm, A.; Dineen, D.; Gibson, T.J.; Karplus, K.; Li, W.; Lopez, R.; McWilliam, H.; Remmert, M.; Soding, J.; et al. Fast, scalable generation of high-quality protein multiple sequence alignments using Clustal Omega. Mol. Syst. Biol. 2011, 7, 539. [CrossRef]

17. Marchitti, S.A.; Orlicky, D.J.; Vasiliou, V. Expression and initial characterization of human ALDH3B1. Biochem. Biophys. Res. Commun. 2007, 356, 792-798. [CrossRef]

18. Kelley, L.A.; Mezulis, S.; Yates, C.M.; Wass, M.N.; Sternberg, M.J.E. The Phyre2 web portal for protein modeling, prediction and analysis. Nat. Protoc. 2015, 10, 845-858. [CrossRef]

19. Waterhouse, A.; Bertoni, M.; Bienert, S.; Studer, G.; Tauriello, G.; Gumienny, R.; Heer, F.T.; de Beer, T.A.P.; Rempfer, C.; Bordoli, L.; et al. SWISS-MODEL: Homology modelling of protein structures and complexes. Nucleic Acids Res. 2018, 46, W296-W303. [CrossRef]

20. Liu, Z.-J.; Sun, Y.-J.; Rose, J.; Chung, Y.-J.; Hsiao, C.-D.; Chang, W.-R.; Kuo, I.; Perozich, J.; Lindahl, R.; Hempel, J.; et al. The first structure of an aldehyde dehydrogenase reveals novel interactions between NAD and the Rossmann fold. Nat. Struct. Mol. Biol. 1997, 4, 317-326. [CrossRef]

21. Steinmetz, C.G.; Xie, P.; Weiner, H.; Hurley, T.D. Structure of mitochondrial aldehyde dehydrogenase: The genetic component of ethanol aversion. Structure 1997, 5, 701-711. [CrossRef]

22. Buchman, C.D.; Hurley, T.D. Inhibition of the Aldehyde Dehydrogenase $1 / 2$ Family by Psoralen and Coumarin Derivatives. J. Med. Chem. 2017, 60, 2439-2455. [CrossRef] [PubMed]

23. Moretti, A.; Li, J.; Donini, S.; Sobol, R.W.; Rizzi, M.; Garavaglia, S. Crystal structure of human aldehyde dehydrogenase $1 \mathrm{~A} 3$ complexed with NAD+ and retinoic acid. Sci. Rep. 2016, 6, 35710. [CrossRef] [PubMed]

24. Khanna, M.; Chen, C.H.; Kimble-Hill, A.; Parajuli, B.; Perez-Miller, S.; Baskaran, S.; Kim, J.; Dria, K.; Vasiliou, V.; Mochly-Rosen, D.; et al. Discovery of a novel class of covalent inhibitor for aldehyde dehydrogenases. J. Biol. Chem. 2011, 286, 43486-43494. [CrossRef]

25. Keller, M.A.; Zander, U.; Fuchs, J.E.; Kreutz, C.; Watschinger, K.; Mueller, T.; Golderer, G.; Liedl, K.R.; Ralser, M.; Kräutler, B.; et al. A gatekeeper helix determines the substrate specificity of Sjögren-Larsson Syndrome enzyme fatty aldehyde dehydrogenase. Nat. Commun. 2014, 5, 4439. [CrossRef]

26. Pemberton, T.A.; Srivastava, D.; Sanyal, N.; Henzl, M.T.; Becker, D.F.; Tanner, J.J. Structural studies of yeast $\Delta(1)$-pyrroline-5-carboxylate dehydrogenase (ALDH4A1): Active site flexibility and oligomeric state. Biochemistry 2014, 53, 1350-1359. [CrossRef]

27. Krogh, A.; Larsson, B.; von Heijne, G.; Sonnhammer, E.L. Predicting transmembrane protein topology with a hidden markov model: Application to complete genomes11Edited by F. Cohen. J. Mol. Biol. 2001, 305, 567-580. [CrossRef]

28. Sonnhammer, E.L.; von Heijne, G.; Krogh, A. A hidden Markov model for predicting transmembrane helices in protein sequences. In Proceedings of the 6 th International Conference on Intelligent Systems for Molecular Biology, Montreal, QC, Canada, 28 June-1 July 1998; Volume 6, pp. 175-182.

29. Hirokawa, T.; Boon-Chieng, S.; Mitaku, S. SOSUI: Classification and secondary structure prediction system for membrane proteins. Bioinformatics 1998, 14, 378-379. [CrossRef] 
30. Horton, P.; Park, K.-J.; Obayashi, T.; Fujita, N.; Harada, H.; Adams-Collier, C.J.; Nakai, K. WoLF PSORT: Protein localization predictor. Nucleic Acids Res. 2007, 35, W585-W587. [CrossRef]

31. Blom, N.; Gammeltoft, S.; Brunak, S. Sequence and structure-based prediction of eukaryotic protein phosphorylation sites. J. Mol. Biol. 1999, 294, 1351-1362. [CrossRef]

32. Kitamura, T.; Takagi, S.; Naganuma, T.; Kihara, A. Mouse aldehyde dehydrogenase ALDH3B2 is localized to lipid droplets via two C-terminal tryptophan residues and lipid modification. Biochem. J. 2015, 465, 79-87. [CrossRef] [PubMed]

33. Dabrowski, M.; Bukowy-Bieryllo, Z.; Zietkiewicz, E. Translational readthrough potential of natural termination codons in eucaryotes-The impact of RNA sequence. RNA Biol. 2015, 12, 950-958. [CrossRef] [PubMed]

34. Chittum, H.S.; Lane, W.S.; Carlson, B.A.; Roller, P.P.; Lung, F.-D.T.; Lee, B.J.; Hatfield, D.L. Rabbit $\beta$-Globin Is Extended Beyond Its UGA Stop Codon by Multiple Suppressions and Translational Reading Gaps ${ }^{\dagger}$. Biochemistry 1998, 37, 10866-10870. [CrossRef] [PubMed]

35. Valle, R.P.; Drugeon, G.; Devignes-Morch, M.D.; Legocki, A.B.; Haenni, A.L. Codon context effect in virus translational readthrough. A study in vitro of the determinants of TMV and Mo-MuLV amber suppression. FEBS Lett. 1992, 306, 133-139. [CrossRef]

36. Von der Haar, T.; Tuite, M.F. Regulated translational bypass of stop codons in yeast. Trends Microbiol. 2007, 15, 78-86. [CrossRef] [PubMed]

37. Steneberg, P.; Samakovlis, C. A novel stop codon readthrough mechanism produces functional Headcase protein in Drosophila trachea. EMBO Rep. 2001, 2, 593-597. [CrossRef]

38. Schueren, F.; Thoms, S. Functional Translational Readthrough: A Systems Biology Perspective. PLoS Genet. 2016, 12, e1006196. [CrossRef]

39. Firth, A.E.; Wills, N.M.; Gesteland, R.F.; Atkins, J.F. Stimulation of stop codon readthrough: Frequent presence of an extended 3' RNA structural element. Nucleic Acids Res. 2011, 39, 6679-6691. [CrossRef]

40. Eswarappa, S.M.; Potdar, A.A.; Koch, W.J.; Fan, Y.; Vasu, K.; Lindner, D.; Willard, B.; Graham, L.M.; DiCorleto, P.E.; Fox, P.L. Programmed Translational Readthrough Generates Antiangiogenic VEGF-Ax. Cell 2014, 157, 1605-1618. [CrossRef]

41. Keeling, K.M.; Wang, D.; Conard, S.E.; Bedwell, D.M. Suppression of premature termination codons as a therapeutic approach. Crit. Rev. Biochem. Mol. Biol. 2012, 47, 444-463. [CrossRef]

42. Geller, A.I.; Rich, A. A UGA termination suppression tRNATrp active in rabbit reticulocytes. Nature 1980, 283, 41-46. [CrossRef] [PubMed]

43. Yamaguchi, Y.; Hayashi, A.; Campagnoni, C.W.; Kimura, A.; Inuzuka, T.; Baba, H. L-MPZ, a novel isoform of myelin P0, is produced by stop codon readthrough. J. Biol. Chem. 2012, 287, 17765-17776. [CrossRef] [PubMed]

44. Labunskyy, V.M.; Hatfield, D.L.; Gladyshev, V.N. Selenoproteins: Molecular pathways and physiological roles. Physiol. Rev. 2014, 94, 739-777. [CrossRef] [PubMed]

45. Hofhuis, J.; Schueren, F.; Nötzel, C.; Lingner, T.; Gärtner, J.; Jahn, O.; Thoms, S. The functional readthrough extension of malate dehydrogenase reveals a modification of the genetic code. Open Biol. 2016, 6, 160246. [CrossRef] [PubMed]

46. Schueren, F.; Lingner, T.; George, R.; Hofhuis, J.; Dickel, C.; Gärtner, J.; Thoms, S. Peroxisomal lactate dehydrogenase is generated by translational readthrough in mammals. Elife 2014, 3, e03640. [CrossRef]

47. Loughran, G.; Jungreis, I.; Tzani, I.; Power, M.; Dmitriev, R.I.; Ivanov, I.P.; Kellis, M.; Atkins, J.F. Stop codon readthrough generates a C-terminally extended variant of the human Vitamin D receptor with reduced calcitriol response. J. Biol. Chem. 2018, 293, 4434-4444. [CrossRef]

48. Pacho, F.; Zambruno, G.; Calabresi, V.; Kiritsi, D.; Schneider, H. Efficiency of translation termination in humans is highly dependent upon nucleotides in the neighbourhood of a (premature) termination codon. J. Med. Genet. 2011, 48, 640-644. [CrossRef]

49. Beier, H.; Grimm, M. Misreading of termination codons in eukaryotes by natural nonsense suppressor tRNAs. Nucleic Acids Res. 2001, 29, 4767-4782. [CrossRef]

50. Brown, C.M.; Stockwell, P.A.; Trotman, C.N.; Tate, W.P. Sequence analysis suggests that tetra-nucleotides signal the termination of protein synthesis in eukaryotes. Nucleic Acids Res. 1990, 18, 6339-6345. [CrossRef]

51. Beznosková, P.; Wagner, S.; Jansen, M.E.; von der Haar, T.; Valášek, L.S. Translation initiation factor eIF3 promotes programmed stop codon readthrough. Nucleic Acids Res. 2015, 43, 5099-5111. [CrossRef] 
52. Roy, B.; Leszyk, J.D.; Mangus, D.A.; Jacobson, A. Nonsense suppression by near-cognate tRNAs employs alternative base pairing at codon positions 1 and 3. Proc. Natl. Acad. Sci. USA 2015, 112, 3038-3043. [CrossRef] [PubMed]

53. Loenarz, C.; Sekirnik, R.; Thalhammer, A.; Ge, W.; Spivakovsky, E.; Mackeen, M.M.; McDonough, M.A.; Cockman, M.E.; Kessler, B.M.; Ratcliffe, P.J.; et al. Hydroxylation of the eukaryotic ribosomal decoding center affects translational accuracy. Proc. Natl. Acad. Sci. USA 2014, 111, 4019-4024. [CrossRef] [PubMed]

54. Houck-Loomis, B.; Durney, M.A.; Salguero, C.; Shankar, N.; Nagle, J.M.; Goff, S.P.; D'Souza, V.M. An equilibrium-dependent retroviral mRNA switch regulates translational recoding. Nature 2011, 480, 561-564. [CrossRef] [PubMed]

55. Brown, C.M.; Dinesh-Kumar, S.P.; Miller, W.A. Local and Distant Sequences Are Required for Efficient Readthrough of the Barley Yellow Dwarf Virus PAV Coat Protein Gene Stop Codon. J. Virol. 1996, 70, 5884-5892. [PubMed]

56. Loughran, G.; Chou, M.-Y.; Ivanov, I.P.; Jungreis, I.; Kellis, M.; Kiran, A.M.; Baranov, P.V.; Atkins, J.F. Evidence of efficient stop codon readthrough in four mammalian genes. Nucleic Acids Res. 2014, 42, 8928-8938. [CrossRef] [PubMed]

57. Jungreis, I.; Lin, M.F.; Spokony, R.; Chan, C.S.; Negre, N.; Victorsen, A.; White, K.P.; Kellis, M. Evidence of abundant stop codon readthrough in Drosophila and other metazoa. Genome Res. 2011, 21, 2096-2113. [CrossRef]

58. Bidou, L.; Hatin, I.; Perez, N.; Allamand, V.; Panthier, J.-J.; Rousset, J.-P. Premature stop codons involved in muscular dystrophies show a broad spectrum of readthrough efficiencies in response to gentamicin treatment. Gene Ther. 2004, 11, 619-627. [CrossRef]

59. Howard, M.T.; Shirts, B.H.; Petros, L.M.; Flanigan, K.M.; Gesteland, R.F.; Atkins, J.F. Sequence specificity of aminoglycoside-induced stop condon readthrough: Potential implications for treatment of Duchenne muscular dystrophy. Ann. Neurol. 2000, 48, 164-169. [CrossRef]

60. Cridge, A.G.; Crowe-McAuliffe, C.; Mathew, S.F.; Tate, W.P. Eukaryotic translational termination efficiency is influenced by the 3' nucleotides within the ribosomal mRNA channel. Nucleic Acids Res. 2018, 46, 1927-1944. [CrossRef]

61. Feng, Y.-X.; Copeland, T.D.; Oroszlan, S.; Rein, A.; Levin, J.G. Identification of Amino Acids Inserted During Suppression of UAA and UGA Termination Codons at the gag-pol Junction of Moloney Murine Leukemia Virus. Proc. Natl. Acad. Sci. USA 1990, 87, 8860-8863. [CrossRef]

62. Namy, O.; Hatin, I.; Rousset, J.P. Impact of the six nucleotides downstream of the stop codon on translation termination. EMBO Rep. 2001, 2, 787-793. [CrossRef] [PubMed]

63. Tork, S.; Hatin, I.; Rousset, J.-P.; Fabret, C. The major 5' determinant in stop codon read-through involves two adjacent adenines. Nucleic Acids Res. 2004, 32, 415-421. [CrossRef] [PubMed]

64. Diop, D.; Chauvin, C.; Jean-Jean, O. Aminoglycosides and other factors promoting stop codon readthrough in human cells. Comptes Rendus Biol. 2007, 330, 71-79. [CrossRef] [PubMed]

65. Perkins, D.N.; Pappin, D.J.C.; Creasy, D.M.; Cottrell, J.S. Probability-based protein identification by searching sequence databases using mass spectrometry data. Electrophoresis 1999, 20, 3551-3567. [CrossRef]

(C) 2019 by the authors. Licensee MDPI, Basel, Switzerland. This article is an open access article distributed under the terms and conditions of the Creative Commons Attribution (CC BY) license (http://creativecommons.org/licenses/by/4.0/). 